\title{
Microbicide drug candidates to prevent HIV infection
}

\author{
Jan Balzarini, Lut Van Damme
}

25 years after the first HIV/AIDS cases emerged in 1981, the disease continues to spread worldwide, with about 15000 new infections every day. Although highly active antiretroviral therapy (HAART) has greatly reduced the rate of HIV infection, and the spread of the epidemic, this effect has largely been seen in developed countries. More than $\mathbf{9 0 \%}$ of HIV-infected people live in developing countries, most of whom do not have access to this treatment. The development of efficient, widely available, and low-cost microbicides (gels and creams can be applied topically before sex) to prevent sexually transmitted HIV infections should be given high priority. We review different categories of microbicide drugs and lead compounds, their mechanism of action, current status of development, and progress in phase III trials.

\section{Introduction}

After sexual exposure to HIV, there are several mechanisms by which the virus can infect an individual, and there is dissent in the scientific community on the relative importance of each of the infection pathways used by the virus. ${ }^{1,2}$ In the genital tract, the virus can enter through the intact stratified vaginal epithelium or the single layer of the cervical columnar epithelium cells (figure). ${ }^{3}$ In the genital and rectal sub-mucosa area, CD4+ T-cells, macrophages, and dendritic cells can then be infected by HIV., ${ }^{4,5}$ The virus can establish infection by attaching its envelope gp120 protein to the CD4 surface protein of T-lymphocytes in conjunction with a chemokine (CXCR4 or CCR5) co-receptor. HIV can also attach its envelope gp120 protein to DC-SIGN, a C-type mannose-specific lectin, expressed by dendritic cells. ${ }^{6-9}$ The underlying molecular mechanisms of HIV transmission by dendritic cells is not fully understood. However, research shows that DC-SIGN can act as an HIV-trans-receptor that efficiently transfers the virus to
CD4+ T lymphocytes shortly after exposure to the virus. This process, known as trans-enhancement of T-cell infection, is independent of DC-SIGN internalisation signals, which means that HIV does not necessarily need to be internalised by these cells to be transferred to $\mathrm{T}$ cells.' Several days after viral exposure, HIV transfer to $\mathrm{T}$ cells continues to occur exclusively through infected dendritic cells that transmit newly synthesised virus particles. In this infection pathway, DC-SIGN cooperates with the HIV entry receptors to facilitate cis-infection of the immature dendritic cells and subsequent HIV transmission to $\mathrm{T}$ cells. This mode of transmission might be physiologically more relevant than the intracellular storage of incoming viruses by the dendritic cells. ${ }^{10}$ Other dendritic cells, Langerhans cells, that are present in the stratified vaginal epithelium, do not express the mannose $\mathrm{C}$-type lectin receptor. Instead, CD4 is well-expressed, but CCR5 and especially CXCR4 are poorly expressed, probably resulting in a rather moderate efficiency of
Lancet 2007; 369: 787-97

Published Online

February 14, 2007 DOI:10.1016/S01406736(07)60202-5

Rega Institute for Medical Research, K U Leuven, B-3000 Leuven, Belgium (ProfJ Balzarini PhD); and CONRAD, Arlington, VA, USA (L Van Damme PhD)

Correspondence to: Prof Jan Balzarini jan.balzarini@rega.kuleuven.be

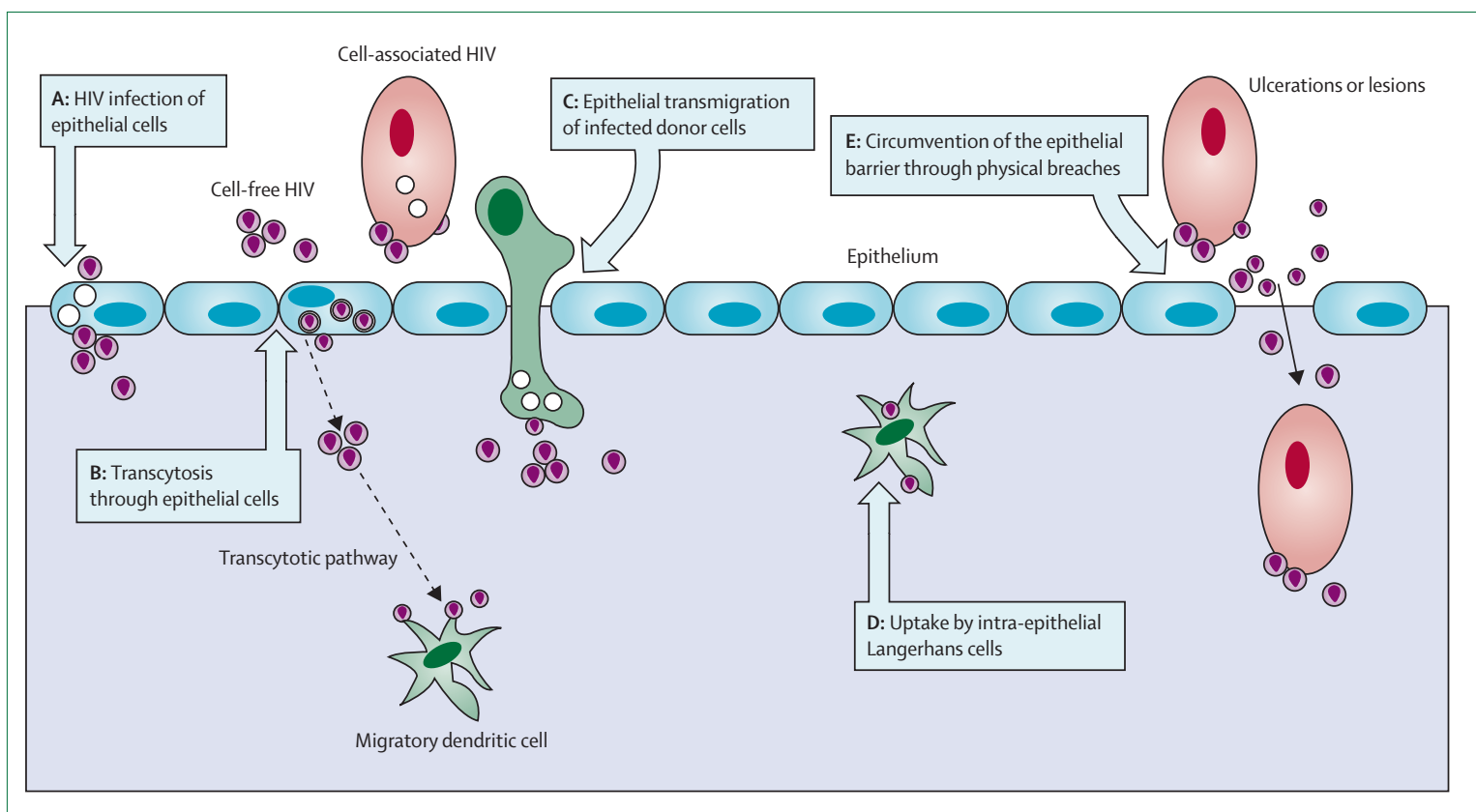

Figure: Potential mechanisms (A-E) for HIV-1 transmission across the mucosal epithelium 


\begin{tabular}{|ll|}
\hline Vaginal, cervical, or rectal mucosa & Mechanism of microbicidal action \\
\hline & $\begin{array}{l}\text { Direct inactivation (ie, detergents or surfactants) } \\
\text { Preservation of vaginal acidic environment } \\
\text { Enhancement or restoration of commensal organisms (eg, lactobacilli) } \\
\text { Physical barrier (ie, gel formulations) }\end{array}$ \\
Tissue or cell surface & $\begin{array}{l}\text { HIV cell receptors and co-receptors } \\
\text { Viral adsorption or fusion with target cells }\end{array}$ \\
Virus surface & $\begin{array}{l}\text { Viral envelope: polyanionic polymers (virus adsorption); envelope } \\
\text { gp120 or gp41 interacting agents (virus entry) }\end{array}$ \\
Inside the cell & $\begin{array}{l}\text { Specific low-molecular weight anti-virals interfering with the } \\
\text { replication cycle of the virus (eg, virus-encoded reverse transcriptase or } \\
\text { integrase) }\end{array}$ \\
\hline Table 1: Target sites and mechanisms of microbicides
\end{tabular}

Panel 1: Properties of an ideal anti-HIV microbicide

- Potent activity against most HIV strains

- Preferably broad activity against other sexually transmitted pathogens

- Direct virucidal activity

- Preservation of microbicidal activity in the presence of seminal fluid

- Effective against both cell-free and cell-associated HIV

- No effect on the structural integrity of vaginal, cervical, or rectal mucosal epithelium

- No effect on vaginal commensal flora, especially lactobacilli

- Preferentially contraceptive properties

- Resistant to acidic, vaginal $\mathrm{pH}$ or enforcing an acidic $\mathrm{pH}$

- Stable at higher, tropical temperatures

- Odourless, colourless, and tasteless

- Compatibility with latex

- Easy to use

- Low cost and readily accessible

- Acceptable to all sexual partners

Langerhans cells to establish a productive HIV infection. ${ }^{11}$ Macrophages also contain mannose-binding C-type lectin receptors that can bind HIV envelope gp120, resulting in subsequent transmission to T cells. ${ }^{12}$ The ideal microbicide should be able to cope with this variety of HIV infection mechanisms, but should also be able to block progressive infection once HIV is intracellular. Thus, HIV prevention would probably need the use of a combination of several microbicide drugs in one formulation that also includes a specific antiretroviral drug.

Microbicides can act through various ways (table 1). They also have varying degrees of specificity: non-specific, moderately specific, or highly HIV-specific. The non-specific and moderately specific microbicides are often active against several sexually transmitted pathogens, and could also have a spermicidal (and thus contraceptive) effect. Potential contraceptive properties, if any, should be well understood and characterised before the drug is advocated for use. Highly HIV-specific microbicides are active solely against HIV, and sometimes exclusively against HIV-1. Non-scientific reasons, such as ease of use and cost, will also determine the choice of candidate microbicide drug for clinical development (panel 1). ${ }^{13,14}$

\section{Non-specific microbicides}

Although the incidence of male-to-female HIV sexual transmission is generally low (transmission probability per act varies from $0 \cdot 0001-0 \cdot 004), 1,15$ its probability increases with viral load in semen, and further increases when the male partners are acutely infected. ${ }^{15}$ Non-specific microbicides can tightly or irreversibly bind to the HIV envelope. Therefore, complete or even incomplete inactivation of cell-free, or cell-associated HIV, or both, in semen by appropriate microbicides would prevent or markedly decrease the probability of virus transmission. Vaginal HIV infection is greatly facilitated by the presence of other sexually transmitted infections. ${ }^{16-18}$ Thus, treatment and prophylaxis for these infections should reduce the likelihood of HIV infection. Detergents or surfactants (surface-acting agents) that destroy the integrity of the viral envelope by solubilising the membrane proteins, and buffering agents that preserve the acidic $\mathrm{pH}$ in the vaginal environment, thereby increasing the instability of the virus particle, are the main compounds in this category.

\section{Detergents or surfactants}

The prototype detergent compound is the non-ionic surfactant nonoxynol (N-9) that forms a chemical barrier between the vaginal mucosa and the ejaculate. However, since N-9 disrupts the phospholipid membrane of cells, it can cause non-specific damage to vaginal epithelium cells, and uterine and cervical tissue, increasing rather than decreasing the likelihood of HIV infection. ${ }^{19,20}$ In a phase III study of this compound, ${ }^{21,22}$ African and Thai female sex workers who applied an N-9 gel (COL-1492) several times a day had a higher rate of HIV infection (14.7 per 100 woman-years) compared with those using a placebo (10.3 per 100 woman-years). Exploratory analysis showed that the treatment group had an increase in genital tract lesions with an epithelial breach, which was linked to a higher incidence of HIV seroconversion. WHO no longer advocates N-9 for HIV-1 prevention. ${ }^{23}$

Sodium dodecyl sulphate (SDS), also called sodium laurilsulfate (SLS), ${ }^{24,25}$ are sulphated (negatively charged) surfactants that denature membrane proteins of pathogens and cells. SLS has inhibited HIV and herpes simplex virus (HSV) in cell culture and in animal models. ${ }^{26}$ The glycoproteins of the HIV envelope are affected by SLS, resulting in a compromised adsorption of the virus to its target cells. ${ }^{27}$ Since SLS can be formulated as a thermoreversible gel, ${ }^{24}$ it could act both as a physical barrier and as a denaturating agent for the external proteins of the exposed pathogens. However, whether long-term application of such surfactants will eventually result in similar side-effects as those of N-9 remains to be seen. 
C31G is a surfactant with potential as a microbicide and spermicide contraceptive. It consists of an equimolar mixture of two surface-active amphoteric agents (alkyl amine $\mathrm{N}$-oxide and an $\mathrm{N}$-alkyl $\mathrm{N}$-dimethylglycine (alkyl betaine) buffered with citric acid, and it disrupts the membrane with its alkyl moiety. ${ }^{28}$ A clinical study has shown that many patients are reluctant to use it because of associated burning sensations. ${ }^{29}$ Bax and colleagues ${ }^{30}$ assessed formulation changes of the surfactant and concluded that $1 \%, 0 \cdot 5 \%$, and $1.7 \%$ co-polymer gel formulations merited further study for safety and efficacy. However, clinical trials of $\mathrm{C} 31 \mathrm{G}$ have recently been discontinued.

\section{Buffering agents}

Maintenance of the acidic $\mathrm{pH}$ in the cervicovaginal fluid is important for innate immunity against infections such as HIV and other pathogens..$^{31}$ By contrast, semen is alkaline $(\mathrm{pH} 7 \cdot 1-8 \cdot 0)$ and increases the vaginal $\mathrm{pH}$, thereby diminishing the natural defense mechanisms. ${ }^{32}$ Normally, the vaginal $\mathrm{pH}$ is acidic $(3 \cdot 5-4 \cdot 5)$ primarily due to the production of lactic acid and $\mathrm{H}_{2} \mathrm{O}_{2}$ by commensal lactobacilli. Lactobacillus suppositories or "probiotics"-living bacterial preparations - can be used to re-acidify the vaginal environment. Since an effective microbicide should not greatly affect the commensal vaginal flora, co-application of probiotics with microbicide drugs could help to maintain the normal vaginal ecology.

Buffering agents include ACIDFORM gel (a bioadhesive, acid-buffering, microbicidal contraceptive gel; Program for Topical Prevention at Conception and Disease; Instead; Dallas, USA) ${ }^{33}$ and BufferGel (an acidic carbopolcontaining buffering microbicide; ReProtect; Baltimore, MD, USA). ${ }^{34}$ Such agents are designed to maintain the acidic vaginal $\mathrm{pH}$ and thus the vaginal defence mechanisms. Both gels have a $\mathrm{pH}$ of 3.5-3.9. BufferGel is being tested in a phase IIb clinical trial. ACIDFORM is being assessed for long-term safety and the prevention of sexually transmitted infections (excluding HIV) in combination with the diaphragm. It is crucial that microbicide formulations have strong bioadhesiveness and retain their viscosity.

Household substances such as lemon juice, "carbonated cola drinks", and vinegar have been suggested to keep the vaginal environment acidic. ${ }^{35}$ However, studies indicate that concentrated lemon juice could irritate and even damage the vaginal lining, making it more, rather than less, likely for the woman to become infected. ${ }^{36}$ Thus, it is important that "potential microbicides" are carefully investigated for side-effects before their use is widely promoted. $^{35}$

\section{Moderately specific microbicides}

A broad variety of anionic polymers that target the adsorption and fusion process of the virus infection are under investigation. They are thought to bind to the viral envelope through their negative charges and block viral entry into the target cells. Although efficient in preventing contact between the cell-free virus and its target cell, these substances generally need to be used in high concentrations to prevent transmission of the cell-associated virus to uninfected cells. ${ }^{37,38}$ However, some substances such as cellulose acetate phthalate have been shown to be effective in this regard in co-cultivation assays of transmission of HIV from virus-infected peripheral blood mononuclear cells (PBMC) to uninfected CEM/X174 cells. ${ }^{39}$ Because of the limited general toxicity of these anionic substances, their therapeutic possibilities are clearly broader than those of the detergents or surfactants. They could be active against not only HIV but also other enveloped viruses such as HSV-2. A broad variety of polyanionic compounds that might qualify as potential candidate microbicide agents are currently in advanced clinical trials. The following products ${ }^{13,14,37,38}$ belong to this category: sulphate esters of $\alpha 1,4$-D-glucose polymers (such as dextran sulfate and dextrin sulfate), polygalactose+3,6-anhydrogalactose copolymers (such as the naturally occurring carrageenans), $\beta 1,4$-glucose polymers (such as cellulose sulphate); sulphated polyacryl and polyvinyl polymers such as sulphated copolymers of acrylic acid with vinyl alcohol (PAVAS) and sulphated polyvinyl alcohol (PVAS); sulphonated polymers such as the naphthalene sulphonate polymer PRO-2000 and poly(styrene-4-sulphonate); polycarboxylates such as acrylic acid polymers (carbomer 9748, buffer gel) and cellulose acetate phthalate (CAP). Their antiviral activities vary depending on the size (molecular weight) and density (charge distribution) of the anionic entity on the molecules. ${ }^{37,38}$ The susceptibility of viruses to the inhibitory effect of these polymers differs depending on whether the viruses use coreceptor CXCR4 (X4 HIV) or CCR5 (R5 HIV). ${ }^{40,41}$ Some polymers (for example PRO 2000 and CAP) inhibit and inactivate both X4 and R5 viruses while other polymers appear effective only against X4 viruses. ${ }^{42,43}$

Sulphate and sulphonate polymers differ in their pharmacological behaviour. Whereas the sulphonate (-SO3) groups are tightly linked to the polymers and highly metabolically stable, the sulfate groups (-OSO3 ) can be subject to hydrolysis (release) by sulphatases present in the vaginal ecosystem, ${ }^{44}$ resulting in inactivation of the compounds. They might also undergo detoxification by converting the negatively charged polymer to an uncharged or lesser charged substance. It is unclear whether the enzymatic activity of bacterial sulphatases is sufficient to substantially affect the antiviral activity of sulphated polymers during the limited time (eg, a few hours) in which the microbicides would be expected to exert their antiviral activities in vivo.

The high molecular weight cellulose sulphate polymer (Ushercell, Global Microbicide Project, Polydex) has been shown in vitro to prevent infection by HIV, herpes simplex virus type 1 (HSV-1) and HSV-2, and proved also inhibitory against Neisseria gonorrhoeae, Chlamydia 
trachomatis, human papillomavirus, and Gardnerella vaginalis. ${ }^{45-47}$ It has been formulated as a $6 \%$ gel, ${ }^{48}$ and found to be promising in three different phase I multi-dose safety and acceptability studies. ${ }^{49-51} \mathrm{~A}$ phase II clinical trial of this compound as a contraceptive completed earlier this year showed promising results. Two phase III HIV prevention trials are ongoing in multiple sites in Africa and India to evaluate its effectiveness against HIV, Neisseria gonorrhoeae, and Chlamydia trachomatis (table 2).

Carraguard, which contains galactose-linked polysaccharides (carrageenan) from the red seaweed Gigartina skottsbergii, blocks HIV infection of cervical epithelial cells and trafficking of HIV-infected macrophages from the vagina to lymph nodes..$^{38,52-54}$ Several phase I and II clinical trials have shown that there are no unacceptable adverse effects of $2 \%$ or $3 \%$ vaginal gel formulations. ${ }^{55-57}$ Carraguard is being assessed in a phase III HIV-prevention trial in three sites in South Africa (table 2).

PRO-2000, a synthetic naphthalene sulfonate polymer (Indevus Pharmaceuticals Inc, Lexington, MA, USA) is active in vitro against HIV at $0.01 \%$ in T lymphocytes, macrophages and cervical explant tissue ${ }^{58}$ and inhibits HSV-1, HSV-2, Chlamydia trachamatis, and Neisseria gonorrhoeae. ${ }^{59}$ PRO-2000 was also shown to be effective in preventing vaginal infection of macaques by a hybrid simian-human immunodeficiency virus (SHIV). ${ }^{60}$ Whereas there is no evidence of systemic absorption of PRO 2000, drug concentrations in cervico-vaginal lavage exceeded $25 \mu \mathrm{g} / \mathrm{mL}$ in $0.5 \%$ and $4 \%$ gel groups at $2 \mathrm{~h}$ after the first dose. ${ }^{61}$ These levels are capable of preventing HIV infection in vitro. ${ }^{61}$ Since some adverse effects were noted in a phase I study using $2 \%$ formulations, which were even more evident with $4 \%$ formulations, a recommendation was made to test the gel further at lower concentrations and dosing frequencies..$^{62}$ One ongoing phase IIb trial is comparing 0.5\% PRO-2000 with BufferGel and condom only; another ongoing phase III trial is comparing $0.5 \%$ with $2 \%$ PRO-2000 gel (table 2).

CAP has been shown to be virucidal against HIV-1 and herpes viruses, and also inhibitory to pathogens of the genital tract. ${ }^{42,62,64}$ CAP blocks infection by both cell-free and cell-associated HIV. ${ }^{39}$ It is the only candidate microbicide in which the active ingredient is provided in the form of micronised (about $1 \mu \mathrm{m}$ diameter) particles. This is expected to assure a lack of systemic absorption. The particles adsorb HIV and force the virus envelope glycoprotein gp41 into a fusion-inactive conformation preventing infection. ${ }^{42,65} \mathrm{CAP}$ was shown to be effective in preventing infection in both high virus titre and repeated low-dose vaginal infection of macaques by SHIV. ${ }^{66,67}$ When vaginally administered in rhesus macaques, CAP was considered safe for repeated use, showing no evidence of penetration into cells that line the vaginal epithelium, nor any adverse effect on vaginal $\mathrm{pH}$ or composition of the vaginal microflora. These favourable data from animal tests could support its use as a potential candidate vaginal microbicide in human clinical trials. ${ }^{68}$

Some dendrimers-polymeric compounds assembled from a central core into a highly branched structure, and often containing negatively charged groups-interfere with HIV entry. $1 \%$ and $3 \%$ gel formulations have been tested in non-human primates and found not to irritate the tissue. ${ }^{69}$ They could also be considered as potential microbicide drug candidates.

\section{Highly specific anti-HIV agents}

HIV-specific microbicides should preferentially block the viral infection cycle before the viral genome gets incorporated in the target cells as proviral DNA (panel 2). Therefore, the sites of virus entry (adsorption and fusion), uncoating, reverse transcription (ssRNA $\rightarrow$ dsDNA) by the virus-encoded reverse transcriptase, and integration of the proviral DNA in the host cell chromosomes by the virus-encoded integrase could be potential targets for microbicidal intervention. Targeting viral entry seems the most promising method, preventing virus particles from entering its susceptible cells and, as shown or expected for most entry inhibitors, also preventing transmission of the virus from virus-infected cells to uninfected cells or transmission of dendritic cell-captured virus to lymphoid cells, or both. However, if the virus has

\begin{tabular}{|c|c|c|c|c|c|}
\hline & Study sponsor & Trial countries & Study design & Target populations & Sample size \\
\hline $\begin{array}{l}\text { BufferGel and PRO2000 } \\
0.5 \% \text { gel }\end{array}$ & HIV Prevention Trial Network & $\begin{array}{l}\text { Malawi, South Africa, Tanzania, USA, } \\
\text { Zambia, Zimbabwe }\end{array}$ & 4-group phase II/IIb & Any sexually active woman & 3220 \\
\hline \multirow[t]{2}{*}{ Cellulose sulfate* } & Global Microbicide Project (GMP-CONRAD) & $\begin{array}{l}\text { Benin, Burkina Faso, India, South Africa, } \\
\text { Uganda }\end{array}$ & 2-group phase III & $\begin{array}{l}\text { High-risk population through own } \\
\text { sexual behaviour }\end{array}$ & 2574 \\
\hline & Family Health International and GMP-CONRAD & Nigeria & 2-group phase III & $\begin{array}{l}\text { High-risk population through own } \\
\text { sexual behaviour }\end{array}$ & 2142 \\
\hline Carraguard & Population Council & South Africa & 2-group phase III & Any sexually active woman & 6270 \\
\hline Pro $20000.5 \%$ and $2 \%$ & UK Microbicides Development Programme & $\begin{array}{l}\text { Cameroon, South Africa, Tanzania, } \\
\text { Uganda, Zambia, Swaziland }\end{array}$ & 3-group phase III & $\begin{array}{l}\text { Any woman who is likely to be } \\
\text { sexually active }\end{array}$ & 11920 \\
\hline Savvy (C31G) & Family Health International & Nigeria & 2-group phase III & $\begin{array}{l}\text { High-risk population through own } \\
\text { sexual behaviour }\end{array}$ & 2142 \\
\hline
\end{tabular}


already entered host cells, or has entered the host through virus-infected cells, specific antiretroviral therapy, targeting one of the replication steps between entry and proviral incorporation could be necessary.

\section{HIV entry inhibitors targeting the cellular side}

Virus entry inhibitors can be directed at the cell level or at the level of the virus gp120/gp41 envelope proteins; both approaches are aimed at preventing the virus from entering its target cells. The main HIV receptor CD4 can be targeted by monoclonal antibodies (mAbs; TNX355) to prevent efficient interaction of this receptor with gp120. ${ }^{70}$ A novel class of cyclotriazadisulfonamide (CADA) molecules could substantiallybutreversibly down-regulate the CD4 receptor, making the cells temporarily resistant to virus infection. ${ }^{71}$ The cytokine co-receptors CXCR4 and CCR 5 are targeted by a variety of agents, mostly CCR 5 inhibitors, including mAbs (PRO-140), ${ }^{72}$ modified

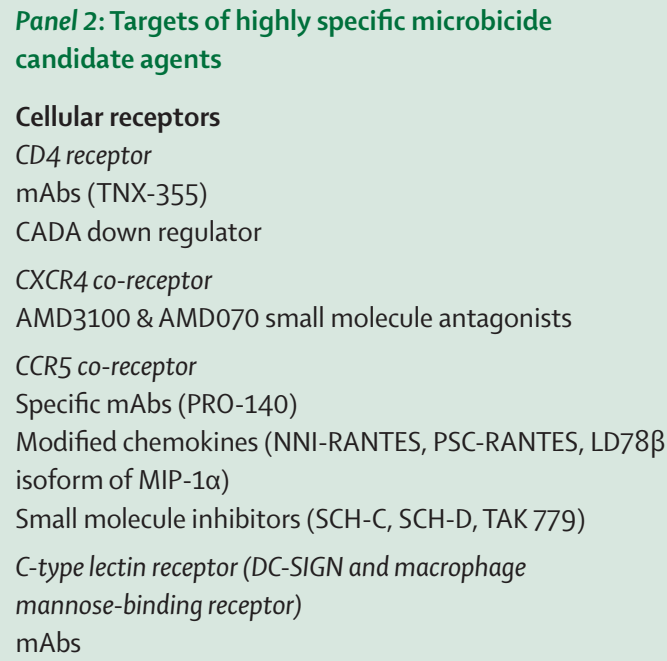

Viral reverse transcriptase (RT)

Nucleotide RT inhibitor (NtRTI)

(R)PMPA [tenofovir (disoproxylfumarate)]

Non-nucleoside RT inhibitor (NNRTI)

TMC-120 (dapivirine), UC-781, MIV-150, and DABO

Viral integrase

Variety of candidate agents chemokines (NNY-RANTES and PSC-RANTES), ${ }^{11,73,74}$ and small molecules (SCH-C, SCH-D, and UK-427857). ${ }^{75-77}$ The modified chemokines not only potently inhibit HIV infection in cell cultures, but their interaction with CCR5 also results in a sustained down-regulation of the receptor. There may, however, be practical pitfalls to using mAbs or modified chemokines as microbicide drugs, such as their considerable production cost, anticipated difficulties with scaling-up and purification, and potential problems with delivery and stability under in-vivo conditions. Therefore, in the long run, the aim should be to focus on the development of potent small-molecule inhibitors. Highly specific small-molecule CXCR4 blockers (the bicyclam AMD3100 and AMD-070) $)^{78,79}$ are under investigation in therapeutic clinical trials and are not aimed at prevention. A broader variety of CCR 5 blockers exists. Combinations of CCR5 and CXCR4 inhibitors in HIV therapy have been considered for systemic use. ${ }^{80}$ CCR5 and CXCR4 antagonists could be combined in a microbicide formulation, or a compound could be designed to target both co-receptors.

The C-type lectin receptor DC-SIGN present on dendritic cells, and other natural mannose-specific receptors on dendritic cells, as well as the macrophage C-type lectin receptor (CLR) are thought to be the major carriers or receptors for the incoming virus. ${ }^{81}$ These cells can catch virus particles by binding to the carbohydrates (mannose) abundantly present on HIV gp120. It is thought that dendritic cells also play a specific and possibly prominent role in the transmission of the virus to the lymphoid tissue. Thus, any efficient way of prophylactic intervention at this stage would be important in blocking the spread of HIV in the host. However, this process cannot be easily targeted by a topical microbicide because of the distance of dendritic cells from the site of drug application. Whereas mAbs directed against CLR is one possible way of intervention, high-mannose oligomer glycans (mannan) may also competitively block virus attachment to the CLR. ${ }^{82,83}$ However, it is unclear whether these type of compounds are capable of efficiently reaching their site of virus interaction when intravaginally administered.

\section{HIV entry inhibitors targeting the viral envelope side}

Several HIV envelope binding agents have been studied. The HIV envelope consists of a trimer of the surface glycoprotein gp120 non-covalently associated with a trimer of the fusion transmembrane glycoprotein gp41. ${ }^{84} \mathrm{~A}$ few mAbs to gp120 and gp41 have a broad neutralising activity against primary HIV-1 isolates. Moreover, researchers have recently shown that a combination of three such mAbs (b12, 2G12, and 2F5) showed neutralisation synergy, ${ }^{85}$ and some protective activity in macaque monkeys challenged with HIV-1 gp120. ${ }^{86}$ Also, the CD4-Ig-2 (PRO-542; engineered CD4 that has a longer plasma half-life than soluble CD4) is a potential candidate 
microbicide agent since it binds to the HIV gp120 envelope and thereby prevents the virus from adsorbing to the cell-associated CD4 receptor." However, the development of small-molecule inhibitors could arguably be prioritised for practical reasons, because they are at least equally, if not more, potent and able to "neutralise" a broad array of primary HIV strains. The recently discovered BMS-806 inhibitor, or one of its closely related derivatives that specifically interact with the CD4 receptor binding site on gp120, ${ }^{87,88}$ could be an example of a potential microbicide candidate drug targeting the HIV gp120 envelope.

Carbohydrate-binding agents (CBA) are especially promising. ${ }^{89}$ The unusually high density of glycans on gp120 (and gp41), almost half of them being high-mannose type glycans,,${ }^{8,9}$ means they are promising targets for candidate microbicide drugs. HIV needs a flexible continuously moving glycan shield to evade immune surveillance, which is why glycans are abundantly present on all HIV clade isolates. Some CBAs have an unusually high genetic barrier and enable "neutralisation" of a broad variety of HIV clades, including HIV-2 strains. ${ }^{90}$ Examples of such CBAs are a1,2-mannose targeting cyanobacterial cyanovirin-N (CV-N) and several $\alpha 1,3-$ and $\alpha 1,6-m a n n o s e-a n d$ GlcNAc-specific plant lectins. ${ }^{90-94}$ Cyanovirin has already been shown in studies on monkeys to be able to prevent SHIV infection when intravaginally or rectally applied as a topical microbicide. ${ }^{95,96}$ CBA are the only drug molecules active against HIV, from which multiple molecules concomitantly bind to the multiple glycans on one single target (HIV envelope) molecule. Therefore, CBA will be much less susceptible to activity loss due to small mutations on the gp120 than mAbs such as 2G12, which is directed against a well-defined glycan or peptide-epitope on gp120. ${ }^{97}$ Attempts are now ongoing to express and release these relatively small lectin proteins (much smaller than $\mathrm{mAbs}$ ) in commensal lactobacilli or streptococci to create a "microbicidal environment" in the vaginal ecology. ${ }^{98-100}$ Lactobacillus jensenii has been engineered to express the functional two-domain CD4 in an attempt to inhibit HIV infectivity by a natural human vaginal bacterial commensal. ${ }^{101}$ Rao and co-workers ${ }^{102}$ reported on an HIV fusion inhibitor peptide secreted by commensal vaginal bacteria as a live microbicide for HIV. Even more interesting is the recognition of small low-molecular-weight molecules"artificial lectins"- that specifically target mannosecontaining glycans on HIV gp120, mimicking the activity and antiviral properties of lectins. ${ }^{103}$ However, potential side-effects of CBA should be monitored, since many cell types in the human organism, including the immune system itself, make use of glycoproteins on their cell surface. However, compared with HIV and prokaryotes, the presence of high-mannose type glycans are rare in glycoproteins of mammalian cells, and thus it is possible that some carefully designed CBA could be highly selective. ${ }^{89}$
With regard to targeting gp41, the clinically approved fusion peptide inhibitor enfuvirtide (T-20), consisting of a 36-aminoacid stretch in the HR2 region of gp41, blocks the formation of a six-helix bundle structure which is critical in the fusion process. Enfuvirtide blocks virus entry at the stage of HIV envelope fusion with the cell membrane. A more potent analogue (T-1249), which also inhibits a broader range of virus strains (and less easily selects for drug resistance), is under clinical evaluation. ${ }^{104}$ As with CBA, the production of small molecules that bind to similar gp41 sites as enfuvirtide, but at a lower cost and more efficiently, are eagerly awaited, and would represent more realistic microbicide candidate drugs in the long run.

\section{Post-entry inhibitors}

Once in the intracellular environment, the virus cannot be blocked by entry inhibitors. It can only be stopped from productive replication and release through inhibition of the virus-encoded reverse transcriptase (RT) or integrase (IN). The HIV RT is a well-exploited target of therapeutic intervention. Several RT inhibitors are currently considered for, or being studied in, clinical phase I or phase II trials as potential microbicides. ${ }^{105}$ The NtRTI tenofovir, widely used in systemic, oral treatment regimens of HIV, is currently in clinical trials as a potential microbicide. It needs to be metabolised intracellularly to be converted to its active form, but has a high genetic barrier. A phase I study with $0.3 \%$ and $1 \%$ vaginal tenofovir gels has been concluded, and a phase II study initiated. ${ }^{106}$ Detectable serum levels of tenofovir have been recorded, but the clinical significance is unclear. ${ }^{106}$ By contrast with N(t)RTIs, the HIV-1-specific NNRTIs have the advantage of a very high therapeutic index and acting directly (without metabolisation) against the virus replication.

The lipophylic, tight-binding NNRTIs such as TMC-120 (dapivirine) and UC-781 are most advanced in clinical trials. UC-781 and TMC-120 effectively prevented HIV infection in cocultures of monocyte-derived dendritic cells and $\mathrm{T}$ cells with a favourable therapeutic index. ${ }^{107}$ UC-781 was shown to bind rapidly to HIV-1 RT with high affinity, and can be effectively "trapped" within the virion. $^{108-110}$ It blocked localised infection and cell dissemination pathways within the human cervical tissue. ${ }^{11,112}$ Similar results were also seen for TMC-120. ${ }^{113}$ A long-term controlled release of TMC-120 from silicone elastomer vaginal rings ${ }^{114}$ could lead to the use of a vaginal ring for the delivery of microbicides. ${ }^{115}$ Vaginal transmission of HIV-1 in hu-SCID mice could be efficiently prevented by a gel formulation of TMC-120. ${ }^{116}$

The low oral bioavailability of such NNRTIs might result in limited systemic absorption, although low levels of TMC-120 could be present in plasma after high intravaginal dosing. Whether such low plasma drug levels are associated with a substantial risk of drug resistance is unclear. Other NNRTIs that might be potential micro- 
bicides are PETT derivatives (MIV-150) and DABO derivatives. ${ }^{117-119}$ The first convincing evidence that HIV integrase inhibitors can clinically act as potent HIV inhibitors is starting to emerge. ${ }^{120}$ As for HIV RT, integrase inhibitors could also be microbicide candidate drugs.

Small molecule anti-HIV inhibitors (for example UC781, TMC120) with low solubility in water or physiological fluids have the potential to form a long-lasting "depot" at sites susceptible to cervicovaginal HIV infection. This could allow application of the microbicide well before sexual intercourse. ${ }^{116}$

\section{Preclinical microbicide model systems for activity, toxicity, and efficacy measurements}

Small-molecule anti-HIV inhibitors could spread systemically and their repeated use in healthy individuals not infected with HIV could result in side-effects that might only become evident some time after use. Therefore, the systemic toxicology, reproductive toxicology, and pharmacodynamics of these compounds must be understood in detail. The traditional in-vitro HIV infection and fusion models for microbicide testing include infection of laboratory cell lines, PBMC, primary macrophages, and dendritic cells by use of a range of laboratory and clinical virus isolates from different HIV clades which have different co-receptor usage. However, ex-vivo human explant studies (human penile, cervical tissue, and mucosal explants) and animal models are important in comparing the efficacies of different microbicide candidates and drug combinations. Although the hu-SCID mouse model has been used for microbicide activity testing in vivo, ${ }^{114}$ the pig-tailed macaque, the Rhesus macaque, and the Cynomolgus monkey model are most relevant for microbicide studies upon vaginal or rectal inoculation of SIV or SHIV..$^{95,96}$ As well as considerations of activity or toxicity in the different cell culture assays and animal models, large-scale production capacity, stability $(\mathrm{pH}$ and temperature), formulation, and costs of the candidate microbicide drug also need to be addressed in the decisions on progression to clinical trials.

The concentrations of anti-HIV compounds in microbicide formulations adequate to prevent vaginal infection of macaques by SHIV exceeds by several orders of magnitude those concentrations sufficient for complete inhibition of infection in in-vitro systems. ${ }^{1,121}$ These findings must also be considered in the design of microbicide formulations for human use and will affect the assessment of safety and economic feasibility of microbicides intended for use in developing countries.

\section{Phase III trials: challenges and successes}

At the start of 2006, more than 60 candidate microbicides were in development. 11 potential microbicide drugs entered phase I clinical trials, and more than 40 are in preclinical development. ${ }^{13}$ One phase II/IIb and five phase III trials are ongoing (table 2). On February 1, 2007, the International AIDS Society (IAS) announced that the two phase III trials of HIV microbicide Candidate Ushercel had been stopped as a precautionary measure due to preliminary results at some sites indicating a potential increased risk for HIV for women who use the compound. ${ }^{63}$ Earlier trials of the same compound involving 500 participants did not indicate safety concerns.

That any of the candidates have made it to phase III clinical trials is a success in itself, given that such trials are huge undertakings with many demands and requirements. Phase III trials need several thousands of women to be enrolled to give a statistically meaningful result-the smallest ongoing phase III trial has a sample size of about 2500 women. Because of the large sample sizes needed, most trials are now undertaken across several countries. Only the Carraguard trial and the Family Health International (FHI) trials are undertaken in one country. Multi-country trials have unique challenges. ${ }^{122}$ All procedures must be standardised, while still allowing for local practices. The trials need to have both ethics and regulatory approval not only in the country of the trial sponsor but also in each country where the trial will be held. The process varies by country. Some countries have national ethics committees as well as institutional ethics boards. In some countries, government committees (eg, the Health Ministry Screening Committee in India) who need to give approval only meet quarterly, which can delay the response to the researchers. Before being able to submit the protocol to ethics committees, all documents that will be shared with participants (eg, informed consent forms, instructions for use) need to be translated into local languages.

In the trial preparation, community involvement is an important aspect ${ }^{123}$ and can be done through different mechanisms. Some trial sites have community advisory boards, others work with a variety of organisations and stakeholders. The liaison with the community helps in different ways: raising the profile of the trial helps with the image of the trial; it could help recruitment and participant retention, and enable any misinformation that might emerge about the trial to be quickly intercepted and dispelled. Some trial organisers draw on expertise from behavioural and social scientists for these aspects.

Recruiting the required number of women and ensuring they stay in the trial can be challenging; all trials use tracing mechanisms and databases to help keep track of the participants. The provision of lunch or entertainment are mechanisms that may help keep women motivated. ${ }^{124-127}$ Another concern is the time that women are "off-product", ${ }^{128}$ which decreases the statistical power of the study. Women might stop using the product because they become pregnant due to non-compliance with the study protocol. Some trials have high pregnancy rates and several studies provide free contraception to try to decrease these rates. Almost all trials keep pregnant women in the trial under the intention-to-treat principle but stop gel use during pregnancy because of the absence of data 
for the effect of the compound on the fetus. Most trials assess adherence through self-reporting-only one trial has a more objective measurement and can detect whether an applicator has been inserted in the vagina or not. ${ }^{129}$

One group, the HIV Prevention Trial Network (HPTN), funded by the US National Institutes of Health, is undertaking a phase II/IIb trial with 3220 women randomised to four groups: Pro 2000 0 · $5 \%$ gel; BufferGel; placebo; and condom-only. This is the only ongoing trial in which women might be randomised to a group that is not given a gel, and the only phase IIb trial to assess the effectiveness of a microbicide. The researchers hope that the results of this trial will give an indication for a future phase III study. The design of these trials is not straightforward. ${ }^{130}$ Regulatory requirements demand follow-up of at least 1 year. In practice, however, a shorter follow-up time could be preferable because participant retention would be higher. Given that there are no reliable surrogate markers for effectiveness against HIV, only phase III trials can reliably indicate whether or not a microbicide is viable; thus, establishing the efficacy level of the microbicide to be used for sample size calculations is highly arbitrary. Several years ago the US Food and Drug Administration held a meeting on the design of phase III microbicide trials that focused on the arguments for and against inclusion of a trial group using condoms-only. The discussion among the current phase III trial groups about trial design and the implications of recent results will help in designing the next trials.

A difficult but important issue in HIV trials is the care of people who seroconvert during the study. Trials of tenofovir prophylaxis ${ }^{131-134}$ were stopped (Cameroon), and others not even started (Cambodia), because of complaints from activists who said the trial participants who seroconverted were not given adequate health care. The provision of care for seroconverters in trials differs from site to site. In some, care is provided in the study clinic; other sites refer participants to existing programmes or to trials for seroconverters. ${ }^{135}$ Another issue is the sample size. Many trials have had to increase their sample size, and one trial had to shut down, because the HIV incidence among the study participants was lower than that used for sample size calculations. Although few seroconversions is good for the participants, trials cannot yield a definite result if there are not enough seroconversions. Different approaches have been proposed to better deal with incidence estimates - eg, the BED assay (a laboratory assay that measures the concentration of HIV-specific antibody, linking prevalence to incidence), and feasibility studies. ${ }^{136-138}$

\section{Conclusion}

Microbicide research and drug development has been built on the understanding of sexual transmission of HIV and progress in anti-HIV drug discovery from research focused on the systemic treatment of the disease. Several drugs that are currently used or considered for use for systemic HIV treatment could probably also qualify for microbicidal use. It is likely that several existing drug derivatives, not suitable for highly active antiretroviral therapy (HAART), could qualify as microbicidal candidate drugs.

It is clear that a single microbicidal agent will not be effective on its own. Instead, a combination of several drugs, preferentially targeting different steps in the viral infection process, will probably ensure the most effective protection. It will be a continuous challenge to decide which of the wide array of candidate drugs are likely to be most effective. The epidemic is continuing to spread, especially in developing countries but also in large areas of Eastern Europe and Asia, and from specific population groups such as drug users and sex workers to the general population. Thus, microbicide research and development and increasing public awareness of the pandemic should be one of the highest priorities in health policy. The academic world, pharmaceutical companies, and governments have a tremendous responsibility to speed-up microbicide research to find efficient microbicide formulations that are affordable, and accessible. Although it is highly advisable to develop only those drugs that give the best preventive results, mathematical models have shown that the use of a microbicide that is only moderately effective could have a substantial effect in tackling the epidemic and improving human health.

\section{Conflict of interest statement}

J Balzarini is a co-inventor of tenofovir for the treatment of HIV infections; he has no other conflict of interest. L Van Damme has no conflict of interest. The corresponding author had full access to all data and had final responsibility for the decision to submit for publication.

\section{Acknowledgments}

The research of JB has been sponsored by the Centers of Excellence of the K.U.Leuven (EF/05/15) and the EMPRO Network of the European Commission. This funding source had no effect on the collection, analysis and interpretation of the data, and in the decision to submit the paper for publication. We thank Christiane Callebaut and

Chantal Biernaux for dedicated editorial help.

References

1 Shattock RJ, Moore JP. Inhibiting sexual transmission of HIV-1 infection. Nat Rev Microbiol 2003; 1: 25-34.

2 Dhawan D, Mayer KH. Microbicides to prevent HIV transmission: overcoming obstacles to chemical barrier protection. J Infect Dis 2006; 193: 36-44.

3 Pope M, Haase A. Transmission, acute HIV-1 infection andthe quest for strategies to prevent infection. Nat Med 2003; 9: 847-52.

4 Patterson BK, Landay A, Andersson J, et al. Repertoire of chemokine receptor expression in the female genital tract: implications for human immunodeficiency virus transmission. Am J Pathol 1998; 153: 481-90.

5 Veazey RS, Marx PA, Lackner AA. Vaginal CD4+ T cells express high levels of CCR5 and are rapidly depleted in simian immunodeficiency virus infection. I Infect Dis 2003; 187: 769-76.

6 Geijtenbeek TB, Kwon DS, Torensma R, et al. DC-SIGN, a dendritic cell-specific HIV-1-binding protein that enhances trans-infection of T cells. Cell 2000; 100: 491-94.

7 Lekkerkerker AN, van Kooyk Y, Geijtenbeek TB. Viral piracy: HIV-1 targets dendritic cells for transmission. Curr HIV Res 2006; 4: 169-76.

8 Leonard CK, Spellman MW, Riddle L, Harris RJ, Thomas JN, Gregory TJ. Assignment of intrachain disulfide bonds and characterization of potential glycosylation sites of the type 1 recombinant human immunodeficiency virus envelope glycoprotein (gp120) expressed in Chinese hamster ovary cells. J Biol Chem 1990; 265: $10373-82$ 
9 Gallaher WR, Ball JM, Garry RF, Martin-Amedee AM, Montelaro RC. A general model for the surface glycoproteins of HIV and other retroviruses. AIDS Res Hum Retroviruses 1995; 11: 191-202.

10 Burleigh L, Lozach PY, Schiffer C, et al. Infection of dendritic cells (DCs), not DC-SIGN-mediated internalization of human immunodeficiency virus, is required for long-term transfer of virus to T cells. J Virol 2006; 80: 2949-57.

11 Kawamura T, Cohen SS, Borris DL, et al. Candidate microbicides block HIV-1 infection of human immature Langerhans cells within epithelial tissue explans. J Exp Med 2000; 192: 1491-1500.

12 Nguyen DG, Hildreth JE. Involvement of macrophage mannose receptor in the binding and transmission of HIV by macrophages. Eur J Immunol 2003; 33: 483-93.

13 Howett MK, Kuhl JP. Microbicides for prevention of transmission of sexually transmitted diseases. Curr Pharm Design 2005; 11: 3731-46.

14 Scholand SJ, DeSimone JA, Pomerantz RJ. Anti-HIV-1 microbicides-'Chemical condoms' designed to limit the scourge of the HIV-1 pandemic. Curr Pharm Design 2005; 11: 3747-56.

15 Pilcher CD, Tien HC, Eron JJ, et al. Brief but efficient: acute HIV infection and the sexual transmission of HIV. J Infect Dis 2004; 189: 1785-92.

16 Aurelian L. Herpes simplex viruses. In: Specter S, Lancz G, ed. In Clinical Virology Manual, 2nd ed. Amsterdam: Elsevier Science, 1992: 473-94.

17 Martin HL Jr, Richardson BA, Nyange P, et al. Vaginal lactobacilli, microbial flora, and risk of human immunodeficiency virus type and sexually transmitted disease acquisition. I Infect Dis 1999; 180: 1863-68.

18 Schwebke JR. Abnormal vaginal flora as a biological risk factor for acquisition of HIV infection and sexually transmitted disease. J Infect Dis 2005; 192: 1315-17.

19 Hillier SL, Moench T, Shattock R, Black R, Reichelderfer P, Veronese F. In vitro and in vivo: the story of nonoxynol 9. J Acquir Immune Defic Syndr 2005; 39: 1-8.

20 Fichorova RN, Tucker DL, Anderson DJ. The molecular basis of nonoxynol-9-induced vaginal inflammation and its possible relevance to human immunodeficiency virus type 1 transmission. J Infect Dis 2001; 184: 418-28.

21 Van Damme L, Ramjee G, Alary M, et al. Effectiveness of COL-1492 a nonoxynol-9 vaginal gel, on HIV-1 transmission in female sex workers: a randomised controlled trial. Lancet 2002; 360: 971-77.

22 Van Damme L. Clinical microbicide research: an overview. Trop Med Int Health 2004; 9: 1290-96.

23 Centers for Disease Prevention and Control. Sexually transmitted diseases treatment guidelines 2002. MMWR Recomm Rep 2002; 51: $1-78$.

24 Roy S, Gourde P, Piret J, et al. Thermoreversible gel formulations containing sodium lauryl sulfate or n-lauroylsarcosine as potentia topical microbicides against sexually transmitted diseases. Antimicrob Agents Chemother 2001; 45: 1671-81.

25 Howett M, Neely E, Christensen N, et al. A broad-spectrum microbicide with virucidal activity against sexually transmitted viruses. Antimicrob Agents Chemother 1999; 43: 314-21.

26 Piret J, Lamontagne J, Bestman-Smith J, et al. In vitro and in vivo evaluations of sodium lauryl sulfate and dextran sulfate as microbicides against herpes simplex and human immunodeficiency virus. J Clin Microbiol 2000; 38: 110-19.

27 Bestman-Smith J, Piret J, Desormeaux A, Tremblay M, Omar R, Bergeron M. Sodium lauryl sulfate abrogates HIV infectivity by affecting viral attachment. Antimicrob Agents Chemother 2001; 45: 2229-37.

28 Wyrick PB, Knight ST, Gerbig DG, et al. The microbicidal agent C31G inhibits Chlamydia trachomatis infectivity in vitro. Antimicrob Agents Chemother 1997; 41: 1335-44.

29 Ballagh SA, Baker JM, Henry DM, Archer DF. Safety of single daily use for one week of C31G HEC gel in women. Contraception 2002; 66: $369-75$.

30 Bax R, Douville K, McCormick D, et al. Microbicides-evaluating multiple formulations of C31G. Contraception 2002; 66: 365-68.

31 Hillier SL. The vaginal microbial ecosystem and resistance to HIV. AIDS Res Hum Retroviruses 1998; 14 (suppl 1): 17-21.
32 Baron S, Singh I, Chopra A, Coppenhaver D, Jingzhi P. Innate antiviral defenses in body fluids and tissues. Antiviral Res 2000; 48: 71-89.

33 Amaral E, Perdigao A, Souza MH, et al. Vaginal safety after use of a bioadhesive, acid-buffering, microbicidal contraceptive gel (ACIDFORM) and a 2\% nonoxynol-9 product. Contraception 2006; 73: $542-47$.

34 Olmsted SS, Khanna KV, Ng EM, et al. Low pH immobilizes and kills human leukocytes and prevents transmission of cell-associated HIV in a mouse model. BMC Infect Dis 2005; 5: 79.

35 Holmes W. Investigating widely available substances as vaginal microbicides. Sexual Health 2004; 33: 73-79.

36 Lackman-Smith C, Snyder BA, Luckenbaugh KA, et al. In vitro assessment of efficacy and cytotoxicity of natural substances proposed as vaginal microbicides against sexual transmission of HIV. Denver: 13th Conference on Retroviruses and Opportunitic Infections, February 6, 2006.

37 Baba M, Schols D, De Clercq E, et al. Novel sulfated polymers as highly potent and selective inhibitors of human immunodeficiency virus replication and giant cell formation. Antimicrob Agents Chemother 1990; 34: 134-38.

38 Pauwels R, De Clercq E. Development of vaginal microbicides for the prevention of heterosexual transmission of HIV. J Acquir Immune Defic Syndr Hum Retrovirol 1996; 11: 211-21.

39 Lu H, Zhao Q, Wallace G, et al. Cellulose acetate 1,2-benzenedicarboxylate inhibits infection by cell-free and cell-associated primary HIV-1 isolates. AIDS Res Hum Retroviruses 2006; 22: 411-18.

40 Moulard M, Lortat-Jacob H, Mondor I, et al. Selective interactions of polyanions with basic surfaces on human immunodeficiency virus type 1 gp120. J Virol 2000; 74: 1948-60.

41 Scordi-Bello IA, Mosoian A, He C, et al. Candidate sulfonated and sulfated topical microbicides: comparison of anti-human immunodeficiency virus activities and mechanisms of action. Antimicrob Agents Chemother 2005; 49: 3607-15.

42 Neurath AR, Strick N, Li YY, Debnath AK. Cellulose acetate phthalate, a common pharmaceutical excipient, inactivates HIV-1 and blocks the coreceptor binding site on the virus envelope glycoprotein gp120. BMC Infect Dis 2001; 1: 17.

43 Neurath AR, Strick N, Li Y-Y. Anti-HIV-1 activity of anionic polymers: a comparative study of candidate microbicides. BMC Infect Dis 2002; 2: 27.

44 Roberton AM, Wiggins R, Horner PJ, et al. A novel bacterial mucinase, glycosulfatase, is associated with bacterial vaginosis. J Clin Microbiol 2005; 43: 5504-08.

45 Christensen ND, Reed CA, Culp TD, et al. Papillomavirus microbicidal activities of high-molecular-weight cellulose sulfate, dextran sulfate, and polystyrene sulfonate. Antimicrob Agents Chemother 2001; 45: 3427-32.

46 Simoes JA, Citron DM, Aroutcheva A, et al. Two novel vaginal microbicides (polystyrene sulfonate and cellulose sulfate) inhibit Gardnerella vaginalis and anaerobes commonly associated with bacterial vaginosis. Antimicrob Agents Chemother 2002; 46: 2692-95.

47 Malonza IM, Mirembe F, Nakabiito, et al. Expanded Phase 1 safety and accetpability study of $6 \%$ cellulose sulfate vaginal gel. AIDS 2005; 19: 2157-63.

48 Anderson RA, Feathergill KA, Diao XH, et al. Preclinical evaluation of sodium cellulose sulfate (Ushercell) as a contraceptive antimicrobial agent. J Androl 2002; 23: 426-38.

49 Mauck C, Weiner DH, Ballagh S, et al. Single and multiple exposure tolerance study of cellulose sulfate gel: a phase I safety and colposcopy study. Contraception 2001; 64: 383-91.

50 Malonza IM, Mirembe F, Nakabiito C, et al. Expanded phase I safety and acceptability study of $6 \%$ cellulose sulfate vaginal gel. AIDS 2005; 19: 2157-63.

51 El-Sadr WM, mayer KH, Maslankowski L, et al. Safety and acceptability of cellulose sulfate as a vaginal microbicide in HIV-infected women. AIDS 2006; 20: 1109-16

52 Schaeffer DJ, Krylov VS. Anti-HIV activity of extracts and compounds from algae and cyanobacteria. Ecotoxicol Environ Saf 2000; 45: 208-27.

53 Zacharopoulos VR, Phillips DM. Vaginal formulations of carrageenan protect mice from herpes simplex virus infection. Clin Diagn Lab Immunol 1997; 4: 465-68. 
54 Perotti ME, Pirovano A, Phillips DM. Carrageenan formulation prevents macrophage trafficking from vagina: implications for microbicide development. Biol Reprod 2003; 69: 933-39.

55 Elias CJ, Coggins C, Alvarez F, et al. Colposcopic evaluation of a vaginal gel formulation of iota-carrageenan. Contraception 1997; 56: 387-89.

56 Kilmarx PH, van de Wijgert JH, Chaikummao S, et al. Safety and acceptability of the candidate microbicide Carraguard in Thai women: findings from a Phase II clinical trial. J Acquir Immune Defic Syndr 2006. [In press] published online Sep 14, 2006.

57 Braunstein S, Morar NS, Gurnede S, et al. Acceptability of carraguard among HIV-infected women and men in a safety trial in South Africa. London: Microbicides 2004 (abstr).

58 Rusconi S, Moonis M, Merrill DP, et al. Naphthalene sulfonate polymers with CD4blocking and anti-human immunodeficiency virus type 1 activities. Antimicrob Agents Chemother 1996; 40: 234-36.

59 Keller MJ, Zerhouni-Layachi B, Cheshenko N, et al. PRO 2000 gel inhibits HIV and herpes simplex virus infection following vaginal application: a double-blind placebo-controlled trial. J Infect Dis 2006; 193: 27-35.

60 Lewis MG, Wagner W, Yalley-Ogunro J, et al. Efficacy of PRO 2000 gel in a macaque model for vaginal HIV transmission. Chicago: 8th Conference on Retroviruses and Opportunistic Infections, 2001.

61 Lacey CJ, Wright A, Weber JN, Profy AT. Direct measurement of in vivo vaginal microbicide levels of PRO 2000 achieved in a human safety study. AIDS 2006; 20: 1027-30.

62 Mayer KH, Karim SA, Kelly C, et al. Safety and tolerability of vaginal PRO-2000 gel in sexually active HIV-uninfected and abstinent HIV-infected women. AIDS 2003; 17: 321-29.

63 International AID Society statement on announcement that two phase II trials of HIV microbicide Candidate Ushercell have been halted. http://www.iasociety.org/images/upload/1263.pdf (accessed Feb 9, 2007)

64 Lu H, Zhao Q, Wallace G, et al. Cellulose acetate 1,2-benzenedicarboxylate inhibits infection by cell-free and cell-associated primary HIV-1 isolates. AIDS Res Hum Retroviruses 2006; 22: 411-18.

65 Neurath AR, Strick N, Jiang S, Li YY, Debnath AK. Anti-HIV-1 activity of cellulose acetate phthalate: synergy with soluble CD4 and induction of "dead-end" gp41 six-helix bundles. BMC Infect Dis 2002; $2: 6$.

66 Boadi T, Schneider E, Chung S, et al. Cellulose acetate 1,2-benzenedicarboxylate protects against challenge with pathogenic $\mathrm{X} 4$ and R5 simian-human immunodeficiency viruses. AIDS 2005; 19: 1587-94.

67 Otten RA, Adams DR, Kim CN, et al. Multiple vaginal exposures to low doses of R5 simian-human immunodeficiency virus: strategy to study HIV preclinical interventions in nonhuman primates. J Infect Dis 2005; 191: 164-73.

68 Ratterree M, Gettie A, Williams V, et al. Safety and distribution of cellulose acetate 1,2-benzenedicarboxylate (CAP), a candidate anti-HIV microbicide in rhesus macaques. AIDS 2005; 19: 1595-99.

69 McCarthy T, Karellas P, Henderson S, et al. Design and preclinical development of dendrimer based topical microbicides for HIV and STI prevention. London: Microbicides 2004 (abstr)

70 Reimann KA, Khunkhun R, Lin W, Gordon W, Fung M. A humanized, nondepleting anti-CD4 antibody that blocks virus entry inhibits virus replication in Rhesus monkeys chronically infected with simian immunodeficiency virus. AIDS Res Hum Retrovirus 2002; 18: 747-55.

71 Vermeire K, Schols D. Cyclotriazadisulfonamides: promising new CD4-targeted anti-HIV drugs. J Antimicrob Chemother 2005; 56: 270-72.

72 Trkola A, Ketas TJ, Nagashima KA, et al. Potent, broad-spectrum inhibition of human immunodeficiency virus type 1 by the CCR 5 monoclonal antibody PRO 140. J Virol 2001; 75: 579-88.

73 Kawamura T, Gulden FO, Sugaya M, et al. R5 HIV productively infects Langerhans cells, and infection levels are regulated by compound CCR5 polymorphisms. Proc Natl Acad Sci USA 2003; 100: 8401-06.

74 Torre VS, Marozsan AJ, Albright JL, et al. Variable sensitivity of CCR5-tropic human immunodeficiency virus type 1 isolates to inhibition by RANTES analogs. J Virol 2000; 74: 4868-76.
75 Pierson TC, Doms RW. HIV-1 entry inhibitors: new targets, novel therapies. Immunol Lett 2003; 85: 113-18.

76 Kazmierski W, Bifulco N, Yang H, et al. Recent progress in discovery of small-molecule CCR5 chemokine receptor ligands as HIV-1 inhibitors. Bioorg Med Chem 2003; 11: 2663-76.

77 O'Hara BM, Olson WC. HIV entry inhibitors in clinical development. Curr Opin Pharmacol 2002; 2: 523-28.

78 Princen K, Schols D. HIV chemokine receptor inhibitors as novel anti-HIV drugs. Cytokine Growth Factor Rev 2005; 16: 659-77.

79 Schols D, Struyf S, Van Damme J, Este JA, Henson G, De Clercq E. Inhibition of T-tropic HIV strains by selective antagonization of the chemokine receptor CXCR4. J Exp Med 1997; 186: 1383-88.

80 Rusconi S, La Seta Catamancio S, Citterio P, et al. Combination of CCR5 and CXCR4 inhibitors in therapy of human immunodeficiency virus type 1 infection: in vitro studies of mixed virus infections. J Virol 2000; 74: 9328-32.

81 Turville SG, Cameron PU, Handley A, et al. Diversity of receptors biding HIV on dendritic cell subsets. Nat Immun 2002; 3: 975-83.

82 Hong PW, Flummerfelt KB, de Parseval A, Gurney K, Elder JH, Lee B. Human immunodeficiency virus envelope (gp120) binding to DC-SIGN and primary dendritic cells is carbohydrate dependent but does not involve $2 \mathrm{G} 12$ or cyanovirin binding sites. Implications for structural analyses of gp120-DC SIGN binding. J Virol 2002; 76: 12855-65.

83 Lin G, Simmons G, Pohlmann S, et al. Differential N-linked glycosylation of human immunodeficiency virus and Ebola virus envelope glycoproteins modulates interactions with DC-SIGN and DC-SIGNR. J Virol 2003; 77: 1337-46.

84 Poignard P, Ollman-Saphire E, Parren PWHI, Burton DR. Gp120 biologic aspects of structural features. Annu Rev Immunol 2001; 19: 253-74.

85 Zwick MB, Parren PW, Saphire EO, et al. Neutralization synergy of human immunodeficiency virus type 1 primary isolates by cocktails of broadly neutralizing antibodies. J Virol 2001; 75: 12198-208.

86 Veazey RS, Shattock RJ, Pope M, et al. Prevention of virus transmission to macaque monkeys by a vaginally applied monoclonal antibody to HIV-1 gp120. Nat Med 2003; 9: 343-46.

87 Wang T, Zhang Z, Wallace OB, et al. Discovery of 4-benzoyl-1-[(4methoxy-1H-pyrrolo[2,3-b]pyridin-3-yl)oxoacetyl]-2-(R)methylpiperazine (BMS-378806): a novel HIV-1 attachment inhibitor that interferes with CD4-gp120 interactions. J Med Chem 2003; 46: 4236-39.

88 Ho HT, Fan L, Nowicka-Sans B, et al. Envelope conformational changes induced by human immunodeficiency virus type 1 attachment inhibitors prevent CD4 binding and downstream entry events. J Virol 2006; 80: 4017-25.

89 Balzarini, J. Targeting the glycans of gp120: a novel approach aimed at the Achilles heel of HIV. Lancet Infect Dis 2005; 5: 726-31.

90 Balzarini J, Van Laethem K, Hatse S, et al. Carbohydrate-binding agents cause deletions of highly conserved glycosylation sites in HIV gp120: a new therapeutic concept to hit the Achilles heel of HIV. J Biol Chem 2005; 280: 41005-14.

91 Boyd MR, Gustafson KR, McMahon JB, et al. Discovery of cyanovirin-N, a novel human imunodeficiency virus-inactivating protein that binds viral surface envelope glycoprotein gp120: Potential applications to microbicide development. Antimicrob Agents Chemother 1997; 41: 1521-30.

92 Bolmstedt AJ, O'Keefe BR, Shenoy SR, McMahon JB, Boyd MR Cyanovirin-N defines a new class of antiviral agent targeting $\mathrm{N}$-linked, high-mannose glycans in an oligosaccharide-specific manner. Mol Pharmacol 2001; 59: 949-54.

93 Mori T, Boyd MR. Cyanovirin-N, a potent human immunodeficiency virus-inactivating protein, blocks both CD4-dependent and CD4-independent binding of soluble gp120 (spg120) to target cells, inhibits sCD4-induced binding of sgp120 to cell-associated CXCR4, and dissociates bound sgp120 from target cells. Antimicrob Agents Chemother 2001; 45: 664-72.

94 Balzarini J, Hatse S, Vermeire, K, et al. Mannose-specific plant lectins from the Amaryllidaceae family qualify as efficient microbicides for prevention of human immunodeficiency virus infection. Antimicrob Agents Chemother 2004; 48: 3858-70.

95 Tsai CC, Emau P, Jiang Y, et al. Cyanovirin-N gel as a topical microbicide prevents rectal transmission of SHIV89.6P in macaques. AIDS Res Hum Retroviruses 2003; 19: 535-41. 
96 Tsai CC, Emau P, Jiang Y, et al. Cyanovirin-N inhibits AIDS virus infections in vaginal transmission models. AIDS Res Hum Retroviruses 2004; 20: 11-18.

97 Calarese DA, Scanlan CN, Zwick MB, et al. Antibody domain exchange is an immunological solution to carbohydrate cluster recognition. Science 2003; 300: 2065-71.

98 Giomarelli B, Arsenijevic S, Pierattelli I, Mori T, Pozzi G. Mucosal delivery of microbicides by commensal bacteria: expression of cyanovirin-N in Lactobacillus. London: Microbicides, 2004 (abstr).

99 Giomarelli B, Provvedi R, Meacci F, et al. The microbicide cyanovirin- $N$ expressed on the surface of commensal bacterium Streptococcus gordonii captures HIV-1. AIDS 2002; 16: 1351-56.

100 Lagenaur LA, Berger EA. An anti-HIV microbicide comes alive. Proc Natl Acad Sci USA 2005; 102: 12294-95.

101 Chang TL, Chang CH, Simpson DA, et al. Inhibition of HIV infectivity by a natural human isolate of Lactobacillus jensenii engineered to express functional two-domain CD4. Proc Natl Acad Sci USA 2003; 100: 11672-77.

102 Rao S, Hu S, McHugh L, et al. Toward a live microbial microbicide for HIV: commensal bacteria secreting an HIV fusion inhibitor peptide. Proc Natl Acad Sci USA 2005; 102: 11993-98.

103 Balzarini J, Van Laethem K, Hatse S, et al. Chemotherapy of human immunodeficiency virus by pradimicin A: a novel therapeutic concept for treatment of glycosylated enveloped viruses. Puerto Rico: 19th International Conference on Antiviral Research, 2006 (abstr).

104 Schneider SE, Bray BL, Mader CJ, et al. Development of HIV fusion inhibitors. J Pept Sci 2005; 11: 744-53.

105 Wainberg MA. The prospect for RT inhibitors as topical microbicides. London: Microbicides, 2004 (abstr)

106 Mayer KH, Maslankowski LA, Gai F, et al. Safety and tolerability of tenofovir vaginal gel in abstinent and sexually active HIV-infected and uninfected women. AIDS 2006; 20: 543-51.

107 Van Herrewege Y, Michiels J, Van Roey J, et al. In vitro evaluation of nonnucleoside reverse transcriptase inhibitors UC-781 and TMC120-R147681 as human immunodeficiency virus microbicides. Antimicrob Agents Chemother 2004; 48: 337-39.

108 Borkow G, Barnard J, Nguyen TM, Belmonte A, Wainberg MA Parniak MA. Chemical barriers to human immunodeficiency virus type 1 (HIV-1) infection: retrovirucidal activity of UC781, a thiocarboxanilide nonnucleoside inhibitor of HIV-1 reverse transcriptase. J Virol 1997; 71: 3023-30.

109 Balzarini J, Naesens L, Verbeken E, et al. Preclinical studies on thiocarboxanilide UC781 as a virucidal agent. AIDS 1998; 12: 1129-38.

110 Hossain MM, Parniak MA. In vitro microbicidal activity of the nonnucleoside reverse transcriptase inhibitor (NNRTI) UC78 against NNRTI-resistant human immunodeficiency virus type 1 J Virol 2006; 80: 4440-46.

111 Zussman A, Lara L, Lara HH, Bentwich Z, Borkow G. Blocking of cell-free and cell-associated HIV-1 transmission through human cervix organ culture with UC781. AIDS 2003; 17: 653-61.

112 Fletcher P, Kiselyeva Y, Wallace G, et al. The nonnucleoside reverse transcriptase inhibitor UC-781 inhibits human immunodeficiency virus type 1 infection of human cervical tissue and dissemination by migratory cells. J Virol 2005; 79: 11179-86.

113 Harman S, Watts P, Shattock R, Griffin G, Van Roej J. TMC120 blocks HIV-1 infection in cellular and human cervical tissue models. London: Microbicides, 2004 (abstr).

114 Malcolm RK, Woolfson AD, Toner CF, Morrow RJ, McCullagh SD. Long-term, controlled release of the HIV microbicide TMC120 from silicone elastomer vaginal rings. J Antimicrob Chemother 2005; 56: 954-56.

115 Woolfson AD, Malcolm RK, Toner CF, et al. Potential use of vaginal rings for prevention of heterosexual transmission of HIV. Am J Drug Deliv 2006; 4: 7-20.

116 Di Fabio S, Van Roey J, Giannini G, et al. Inhibition of vaginal transmission of HIV-1 in hu-SCID mice by the non-nucleoside reverse transcriptase inhibitor TMC120 in a gel formulation. AIDS 2003; 17: 1597-604.
117 Öberg B, Zhang H, Vrang L, Bottiger D. MIV-150, a potent HIV-1 inhibitor suitable for use in microbicides. London: Microbicides 2004 (abstr).

118 D'Cruz OJ, Uckun FM. Dawn of non-nucleoside inhibitor-based anti-HIV microbicides. J Antimicrob Chemother 2006; 57: 411-23.

119 Turpin JA. Considerations and development of topical microbicides to inhibit the sexual transmission of HIV. Expert Opin Investig Drugs 2002; 11: 1077-97.

120 Reeves JD, Piefer AJ. Emerging drug targets for antiretroviral therapy. Drugs 2005; 65: 1747-66.

121 Veazey RS, Klasse PJ, Schader SM, et al. Protection of macaques from vaginal SHIV challenge by vaginally delivered inhibitors of virus-cell fusion. Nature 2005; 438: 99-102.

122 Caraway J, Van Damme L, Avecedo N. Organizing and implementing a multi country RCT. London: Microbicides 2004 (abstr).

123 Frohlich J, Karim QA, Mlotshwa M, et al. Preparing research naive populations for participation in rural KwaZulu Natal, South Africa. London: Microbicides, 2004 (abstr).

124 Govinden R, Ramjee G. Successful strategies for participant accrual and retention. London: Microbicides 2004 (abstr)

125 Mirembe BG, Mirembe F, Nakabiito C, Nakinto N, Muhwezi E. Strategies for recruitment, retention and adherence to study procedures for Microbicide Phase III trial-Uganda. London: Microbicides, 2004 (abstr).

126 Giai-Minietti L, Naidoo K, Chetty N, et al. Participant retention strategies in an ongoing Phase III Carraguard microbicide trial in Durban, South Africa. London: Microbicides 2004 (abstr).

127 Maslankowski L, Whittington S, Prince J, et al. Retention is everybody's job: successes from the University of Pennsylvania site of the HIV Prevention Trials Network (HPTN) 035 (a Phase IIB/III Trial of Buffergel and Pro2000). London: Microbicides, 2004 (abstr).

128 Trussell J, Dominik R. Will microbicide trials yield unbiased estimates of microbicide efficacy ? Contraception 2005; 72: 408-13.

129 Wallace A, Thorn M, Maguire RA, Sudol KM, Phillips DM. Assay for establishing whether microbicide applicators have been exposed to the vagina. Sex Transmiss Dis 2004; 31: 465-68.

130 Nunn A, Rutterford C, Hayes R, McCormack S. Proving efficacy in microbicide trials: what design, how many women and for how long? London: Microbicides, 2004 (abstr).

131 Ramjee G. Provision of care in HIV prevention trials-whose responsibility? Viewpoint of the researcher. London: Microbicides, 2004 (abstr).

132 Page-Shafer K, Saphonn V, Sun LP, et al. HIV prevention research in a resource-limited setting: the experience of planning a trial in Cambodia. Lancet 2005; 366: 1499-1503.

133 Mills E. Tenofovir trials raise ethical issues. HIV AIDS Policy Law Rev 2005; 10: 31-32.

134 Singh JA, Mills EJ. The abandoned trials of pre-exposure prophylaxis for HIV: what went wrong ? PloS Med 2005; 2: e234.

135 WHO/UNAIDS consultation report, Geneva, 2003. AIDS 2004; 18: $1-12$.

136 Frohlich J, Mkhize M, Carrara H, et al. Establishing appropriate high HIV incidence rate cohorts for Phase IIB/III microbicide trials: experience from rural KwaZulu Natal, South Africa. London: Microbicides 2004 (abstr).

137 Coplan P, Malonza I, Mitchnick M, Rosenberg Z. Methods to estimate HIV-1 incidence among study populations prior to microbicide efficacy trials. London: Microbicides, 2004 (abstr).

138 Stevens G, Kamali A, Sanders E, et al. Preparation for efficacy trials: estimating HIV incidence from Kenyan and Ugandan prevalent specimens using the HIV-1 BED IgG Capture EIA Incidence Assay. London: Microbicides, 2004 (abstr). 